\title{
O primado do direeito e as exclusões abissais: reconstruir velhos conceitos, desafiar o cânone
}

SARA ARAÚJO"

\section{Resumo}

O direito moderno eurocêntrico é um instrumento poderoso de reprodução do colonialismo, promovendo exclusões abissais e circunscrevendo o horizonte de possibilidades à narrativa linear de progresso. A linha abissal é, pois, tanto epistemológica como jurídica. Do outro lado da linha, múltiplos universos jurídicos são desperdiçados, invisibilizados e classificados como inferiores, primitivos, locais, residuais ou improdutivos. Este texto assume o desafio de cruzar as Epistemologias do Sul com a sociologia do direito. Mais concretamente, recupera o conceito de pluralismo jurídico, reconfigurando-o como instrumento de ampliação do presente, enquanto ecologia de direitos e de justiças. Começo por mostrar como a imposição global do primado do direito é um mecanismo de expansão do projeto capitalista e colonial, argumentando que a colonialidade jurídica mimetiza a colonialidade do saber. Em seguida, argumento que o reconhecimento do pluralismo jurídico não envolve necessariamente a superação do modelo expansionista. Finalmente, defendo a ampliação do cânone jurídico pela dilatação do leque de experiências conhecidas, um processo que compreende o reconhecimento dos direitos invocados no âmbito de uma legalidade cosmopolita subaltena e a concretização de uma sociologia das ausências atenta aos direitos enunciados fora das lutas jurídicas formuladas nos termos modernos do direito e da política. ${ }^{1}$

\footnotetext{
${ }^{*}$ Centro de Estudos Sociais da Universidade de Coimbra (Portugal)

${ }^{1}$ Este artigo foi elaborado no âmbito do projeto de investigação "ALICE - Espelhos Estranhos, Lições Imprevistas: Definindo para a Europa um novo modo de partilhar as experiências do Mundo", coordenado por Boaventura de Sousa Santos (alice.ces.uc.pt) no Centro de Estudos Sociais da Universidade de Coimbra - Portugal. O projeto é financiado pelo Conselho Europeu para a Investigação, 7o Programa Quadro da União Europeia (FP/2007-2013) /ERC Grant Agreement n. [269807]".
} 
Palavras-chave: Epistemologias do Sul. Estado de direito. Colonialidade jurídica. Pluralismo jurídico. Ecologia de direitos e de justiças.

\title{
The rule of law and the abyssal exclusions: rebuilding old concepts, challenging the canon
}

\begin{abstract}
Modern Eurocentric law is a powerful instrument for the reproduction of colonialism, promoting abyssal exclusions and circumscribing the horizon of possibilities to the modern linear narrative of progress. The abyssal line is, consequently, as much epistemological as it is legal. Across the line, a multiplicity of legal universes is wasted, invisibilised and classified as inferior, primitive, local, residual or unproductive. This paper takes on the challenge of crossing Epistemologies of the South and sociology of law. In particular, it recovers the concept of legal pluralism, reconfiguring it as an instrument of expansion of the present as part of an ecology of law and justices. I begin by showing how the global imposition of the rule of law is a mechanism of expansion of the capitalist and colonial project, arguing that legal coloniality mimics coloniality of knowledge. Subsequently, I demonstrate how the recognition of legal pluralism does not necessarily mean overcoming the expansionist model. In conclusion, I argue for the broadening of the legal canon with the extension of the range of known legal experiences, a process that requires the recognition of rights claimed as cosmopolitan subaltern legality and a sociology of absences of the law of the most silenced oppressed which are expressed in more invisible dimensions, voiced outside of the legal struggles formulated in the modern terms of law and politics.
\end{abstract}

Keywords: Epistemologies of the South. Legal coloniality. Legal pluralism. Ecology of law and justice. 


\section{Introdução}

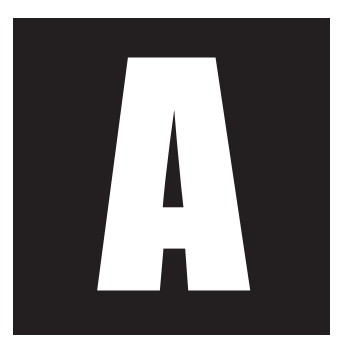

modernidade eurocêntrica é um projeto tanto epistemológico quanto jurídico. Se a ciência moderna estabelece os parâmetros da sociedade civilizada, o primado do direito assegura a sua tradução em limites a que os sujeitos são submetidos e em mapas que circunscrevem o horizonte de possibilidades. Os mapas são delineados pela linha jurídica abissal, para lá da qual fica o impossível. As Epistemologias do Sul (Santos, 2014a) devem, pois, dialogar com a sociologia do direito, ao mesmo tempo que a desafiam, identificando exclusões produzidas por conceitos eurocêntricos, criando ou recriando teorias e metodologias, ampliando ou reformulando velhas questões e acrescentando novas perguntas. Este artigo pretende ser um contributo nesse sentido.

Reconhecendo que o direito moderno é uma invenção ocidental, constitutiva do mito ocidental do progresso (Fitzpatrick, 1992), um localismo globalizado (Santos, 2008), construído a partir de um etnocentrismo jurídico, e imposto por via da colonialidade jurídica, o conceito de pluralismo jurídico deve ser apropriado pelas Epistemologias do Sul não apenas como reação ao mito do centralismo jurídico (Griffiths, 1986), mas enquanto elemento de uma ecologia de direitos e de justiças, que introduza na discussão política universos jurídicos e políticos excluídos e classificados como inferiores, primitivos, locais, residuais ou improdutivos. Se a justiça social global depende da justiça cognitiva global e se esse objetivo envolve um exercício de ecologia de saberes que combate o desperdício da experiência (Santos, 2007), exige, também, um exercício jurídico epistémico que permita o reconhecimento da pluralidade jurídica e dos seus significados políticos sem sobrepor diferença e desigualdade. 
Assim, a questão clássica de Boaventura de Sousa Santos, sobre a possibilidade de o direito ser emancipatório (Santos, 2002), e a velha interrogação dos estudos do pluralismo jurídico, sobre o potencial de democratização da justiça informal, costumeira ou tradicional, são fundidas numa abordagem que recusa as dicotomias modernas e a romantização, quer do direito moderno, quer dos direitos dos oprimidos. Nos espelhos estranhos que as Epistemologias do Sul propõem, ${ }^{2}$ procuro incompletudes e, no desafio das aprendizagens jurídicas recíprocas situo o horizonte de chegada desta proposta. Não é um exercício simples. Como coloca Thomas Duve, na introdução de um livro recente sobre a história jurídica: como é que paramos de projetar os nossos próprios conceitos e categorias a realidades diferentes daquelas em que os mesmos emergiram? O autor recorre ao conceito de "histórias jurídicas emaranhadas", cuja virtude maior assenta na transformação da matriz de questionamento, visto não permitir o luxo de um ponto de partida (Duve, 2014: 7). É precisamente na desconstrução do direito moderno como ponto de partida que reside o grande desafio.

$\mathrm{O}$ artigo está dividido em três momentos. No primeiro, argumento que a expansão do primado do direito é uma expressão da colonialidade jurídica que mimetiza a colonialidade do saber, excluindo do mapa a imensa diversidade jurídica que existe no mundo. No segundo, mostro como o reconhecimento do pluralismo jurídico não envolve necessariamente a superação do modelo colonial capitalista, sendo um conceito instrumentalizável para a operacionalização de modelos reacionários, assentes em conceções dualistas que promovem a exclusão. Finalmente, defendo a ampliação do cânone jurídico pela dilatação do leque de experiências jurídicas conhecidas, um processo que impõe o reconhecimento dos direitos reivindicados no âmbito de uma legalidade cosmopolita su-

\footnotetext{
${ }^{2}$ Os espelhos estranhos ou marginais são uma metáfora do projeto Alice que convida a ver o mundo a partir de perspetivas diferentes (ver alice.ces.uc.pt).
} 
balterna e uma sociologia das ausências dos direitos dos oprimidos mais silenciados que se expressam em dimensões mais invisíveis, enunciando as suas reivindicações fora das lutas jurídicas formuladas nos termos modernos do direito e da política. ${ }^{3}$

\section{A expansão do primado do direito e a colonialidade jurídica}

O conceito de Estado de direito há muito deixou de se circunscrever ao universo restrito dos juristas. Transformado em palavra da moda, de tão usado, acabou perdendo clareza. É destas ideias que partem Ugo Mattei e Laura Nader num livro em homenagem a Edward Said, ${ }^{4}$ no qual sustentam a necessidade de os estudos sobre colonialismo e imperialismo atribuírem mais atenção ao papel do direito, analisarem o lado negativo do Estado de direito e refletirem, a partir de trabalhos sobre o colonialismo europeu, sobre o "orientalismo jurídico", o direito e o desenvolvimento como imperialismo jurídico, bem como sobre a guerra contra o terror. Empenhados nesse objetivo, os autores desenvolvem a tese de que o primado do direito é um modelo que promove a expropriação: o acordo da Organização Internacional do Comércio, o Fundo Monetário Internacional, os condicionalismos do Banco Mundial e a natureza etnocêntrica de muitos discursos sobre direitos impõem um paradigma jurídico que legitima o extrativismo e a pilhagem. Defendem que, no contexto do colonialismo e do imperialismo, o primado do direito pode resultar em desordem e não em ordem, promovendo a continuidade da opres-

\footnotetext{
${ }^{3}$ Sobre a sociologia das ausências e das emergências, ver Santos (2006).

${ }^{4}$ Edward Said, autor da obra "Orientalism" (Said, 1978), que aborda as representações do Ocidente sobre o Oriente, é apontado como um dos fundadores dos Estudos Pós-coloniais.
} 
são, em vez da interrupção da prática colonial (Mattei; Nader, 2008). ${ }^{5}$ Associada às ideias de racionalidade, neutralidade, objetividade e justiça, a linguagem jurídica moderna assume, pois, um papel fundamental na legitimação do modelo dominante, colonial e capitalista, difundindo uma alegada "ordem natural" que certifica os valores e as metas da globalização capitalista neoliberal (Chimni, 2006).

Instituições internacionais, como as acima mencionadas, têm-se empenhado na exportação do direito ocidental para o mundo homogeneizado nessa categoria de "outro", um vazio imaginado, sem nada a ensinar e que deve aprender da superioridade ocidental (Santos, 2014a). Esta trasladação não é uma novidade do final do século XX. James Whitman, num artigo sobre o imperialismo jurídico ocidental, afirma que assistimos hoje ao mais recente episódio de uma longa história de exportação do direito, que começou antes da conquista Ibérica da América Latina, remontando à antiguidade (imposições jurídicas de cidade-estado para cidade-estado) e podendo ser encontrada também na Idade Média (a cidade ditava o modelo jurídico do campo) (Whitman, 2009). Ronald Janse (2013) reconhece que a promoção do primado do direito tem uma história longa, tendo assumido diferentes formas e vários nomes, mas argumenta que, nos anos 1980, esse processo ganha proporções sem precedentes. Janse recorda uma frase usada em finais dos anos 1980 por Thomas Carothers,

\footnotetext{
${ }^{5} \mathrm{O}$ Estado de direito é considerado pelos autores ilegal, por exemplo, quando conceitos como o de terra mullius (terras alegadamente desocupadas que na verdade estão ocupadas) são usados para justificar a expansão; quando se recorre a promessas ilegais ou enganadoras para cooptar ou comprar legisladores; quando a lei é produzida por legisladores eleitos em processos eleitorais duvidosos. Os autores argumentam que, quando legislação sobre privatização, imposta a partir de fora, proporciona uma negociação a preços muito baixos à custa das pessoas, o Estado de direito é um veículo de pilhagem e não de legalidade. Afirmam, ainda, que a democracia, o primado do direito, o desenvolvimento, os direitos humanos internacionais e os argumentos sobre a "ausência" configuram, na paisagem atual, uma forte componente da retórica da legitimação da extração internacional corporativista (Mattei; Nader, 2008).
} 
num artigo da Foreign Affairs: não se pode passar por um debate sobre política internacional, sem que alguém proponha o primado do direito como solução para os problemas do mundo. Janse defende que tal observação faz hoje ainda mais sentido, invocando-se mais argumentos e havendo mais recursos aplicados e mais instituições envolvidas na expansão jurídica ocidental, do que em qualquer momento do passado (idem).

Whitman (2009) argumenta que o trabalho de Mattei e Nader não observa além da obsessão pelo lucro, desconsiderando que, desde funcionários do Banco Mundial a ativistas dos direitos humanos, sempre se encontra quem esteja convencido de uma vocação para difundir a sabedoria pelo resto do mundo. No entanto, Mattei e Nader reconhecem precisamente que o Estado de direito, consequência da parca discussão sobre o conceito, é quase sempre conotado positivamente e associado à noção de democracia (Mattei; Nader, 2008). Na verdade, são menos relevantes as intenções de cada indivíduo do que a ideologia assente numa alegada superioridade das instituições e dos modelos ocidentais, alimentada por uma estrutura moderna capitalista e colonialista. A chave está, pois, num argumento que o próprio James Whitman coloca nas suas conclusões: os reformistas que promovem a discussão do direito não se veem como herdeiros de uma tradição expansionista, mas como agentes de uma verdade universal (Whitman, 2009).

Se as relações políticas mudaram com o fim político dos impérios coloniais, as narrativas hegemónicas, sobre as quais assentou a alegada superioridade dos países do Norte, não foram decisivamente postas em causa e são constitutivas do projeto da modernidade. O colonialismo europeu deixou um legado de injustiça, assente na colonialidade do poder (Quijano, 2009) e alimentado por uma estrutura colonizadora responsável pela marginalização de sociedades, culturas e seres humanos (Mudimbe, 1988). Ainda que seja estabelecida uma horizontalidade política formal, enquanto 
couber a uma das partes a definição do cânone e a linguagem em que este se expressa, os saberes, as normas e as práticas diferentes ou que se exprimem de outro modo tendem a ser inferiorizados e invisibilizados.

Como a ciência moderna, a alegada universalidade do direito assenta num etnocentrismo epistemológico, ou num eurocentrismo, que sustenta a "falácia do deslocamento" (Dussel, 2013), ${ }^{6}$ a "falácia do determinismo" e a "falácia do desaparecimento do Sul" (Santos, 2008). ${ }^{7}$ O direito moderno é o duplo da ciência e, se esta é responsável por aquilo que foi designado "epistemicídio", a conceção moderna de direito legitimou o "juricídio" (Santos, 1995; Santos 2011). O direito moderno ignorou ter um lugar de enunciação e reivindicou universalidade e poder para definir o futuro global. Na análise de George Galindo (2014), os transplantes jurídicos contemporâneos são alimentados pelo desfasamento da modernidade entre experiências e expectativas, gerindo um desequilíbrio que resulta das grandes promessas não cumpridas, com recurso à ideia de progresso e a prognósticos abstratos. O peso sobrestimado atribuído aos agentes internacionais e suas imposições, marcante na historiografia jurídica, foi designado por "modelo difusionista da receção", por assentar na cegueira sobre a complexidade dos encontros jurídicos (Duve, 2014: 8, 9).

A metáfora do pensamento abissal é uma ilustração da colonialidade do pensamento moderno e a ciência e o direito são as suas manifestações mais bem conseguidas (Santos, 2007). De acordo com esta imagem, o pensamento moderno impõe e estabelece os limites de uma linha abissal que divide o mundo entre o universo "deste lado da linha" e o universo

\footnotetext{
${ }^{6}$ Este conceito denuncia o erro de tomar as realidades europeias e norte-americanas como realidades globais (Dussel, 2013).

${ }^{7}$ A falácia do determinismo nega a possibilidade de alternativas e a falácia do desaparecimento do Sul assenta na recusa em reconhecer hierarquias, bem como a ideia de que o Norte tem a aprender com o Sul (Santos, 2008).
} 
"do outro lado da linha". O que acontece do lado de lá não conta (outros conhecimentos, outros direitos), é invisível, não existe ou pelo menos não existe numa lógica de simultaneidade, visto estar sujeito à flecha do tempo linear, que classifica como atrasado tudo o que é assimétrico em relação ao lado de cá, definido como avançado. Tornada invisível, a realidade do lado lá não compromete a universalidade do que se propõe deste lado. No campo jurídico, é ao direito do Estado ou internacional que cabe o poder de determinar o legal e o ilegal. Legal e ilegal perante a lei são as únicas formas relevantes de existência e, nesse sentido, a distinção entre ambos é uma distinção universal. Assim, fica de fora o território sem lei, fora da lei, o território do a-legal, ou mesmo do legal e ilegal de acordo com direitos (Santos, 2007).

Ainda que Santos reflita largamente sobre os papéis do direito e da ciência na construção do mundo moderno (Santos, 2002) e desenvolva uma proposta de direitos humanos interculturais (Santos, 2013), as Epistemologias do Sul têm-se centrado sobretudo na forma como a ciência moderna alimentou a colonialidade, nomeadamente com o desenvolvimento das cinco monoculturas que alimentam a razão metonímica. Ao assumir a parte como um todo, esta é responsável pela imensidão de experiência desperdiçada. A monocultura do saber e do rigor do saber transforma a ciência moderna e da alta cultura em princípios únicos de verdade e qualidade estética. Tudo o que não reconhece, não existe ou é irrelevante. $\mathrm{A}$ monocultura do universal e do global emerge como consequência direta da monocultura do saber: arrogando-se universal e excluindo o mundo que não se encaixa nos seus padrões, tudo o que é local ou particular é invisibilizado pela lógica da escala global. A monocultura da produtividade capitalista vive numa relação simbiótica com a monocultura do saber. A ciência moderna assenta nos princípios que servem à produtividade capitalista. Todo o outro conhecimento é invisibilizado, porque todo o outro 
tipo de produção é desvalorizado. A não existência aparece sob a forma de improdutivo. A monocultura da naturalização das diferenças consiste na distribuição das populações por categorias que identificam diferença com desigualdade e permitiu, pois, legitimar a dominação e a exploração. A monocultura do tempo linear produz a não existência pela "não contemporaneidade do contemporâneo". As dicotomias em que assenta a compreensão ocidental do mundo são, pois, nutridas de uma lógica evolucionista, que sobrepõe diferença, inferioridade e anacronismo. O outro não é só selvagem, é atrasado, primitivo, arcaico. O padrão civilizacional da modernidade é a imagem do futuro para o resto do mundo, que pode estar mais perto ou mais longe de o alcançar (Santos, 2006).

Como duplo da ciência, o direito espelha-se nas cinco monoculturas da razão metonímica. A monocultura jurídica despreza os direitos locais e os universos jurídicos que regem formas de produtividade não capitalistas e classifica como irrelevantes, locais, improdutivas, inferiores e primitivas as formulações jurídicas não modernas. É a estes universos jurídicos que as transladações jurídicas pretendem sobrepor-se, seja como forma de construção do bom ambiente de negócios pelas instituições financeiras internacionais, seja pela imposição de uma carta de direitos humanos de matriz eurocêntrica. O conceito de pluralismo jurídico contraria a cartografia jurídica moderna que ficou conhecida como centralismo jurídico, mas não altera necessariamente estas classificações. Como veremos nas próximas páginas, nos últimos anos, perante dificuldades, as instituições internacionais têm vindo a apropriar o conceito. Uma categoria que nasceu com um potencial emancipatório é hoje instrumentalizada para promover a ordem colonialista, capitalista e neoliberal. 


\section{O insucesso das reformas jurídicas e a instrumentalização do pluralismo jurídico. A promoção do modelo bifurcado}

Os investimentos que ocorrem a partir dos anos 1980 na promoção do Estado de direito não se traduziram em concretizações proporcionais. Como afirma Ronald Janse (2013), existem diferentes razões para explicar a popularidade deste modelo, mas os resultados não são uma delas. Entre os doadores, uma das explicações recentes mais populares para explicar o insucesso das reformas é o facto de se terem centrado exclusivamente nos sistemas jurídicos estatais (Janse, 2013). Assim, depois de décadas a tentarem impor à força um modelo universal de Estado de Direito, assente numa conceção jurídica centralista nos designados países em desenvolvimento, o Banco Mundial e outras agências internacionais descobriram o "pluralismo jurídico" e decidiram acomodá-lo nos seus relatórios.

Não se tratou de uma epifania, mas da impossibilidade de ignorar o fracasso em que se traduziram as políticas impositivas universais e a desvalorização dos contextos. Como afirma Janse, ainda que o trabalho crítico dos académicos e de alguns profissionais destacados tenha desempenhado um papel na viragem para o pluralismo jurídico, a verdade é que doadores acabaram por aprender da maneira mais difícil que a reforma jurídica imposta tem limites evidentes (Janse, 2013). Uma vez que o sistema de justiça não responde a reformas e ações de capacitação impostas de cima para baixo, buscam-se agora soluções através da justiça informal para promover a estabilização do Estado de Direito. Foi nesse sentido que se concluiu que poderia ser útil conhecer o que a sociologia e a antropologia do direito andavam a produzir e, como tal, fizeram-se conferências e patrocinaram-se publicações, convidando alguns nomes bastante considerados na área para reproduzirem o que há tantos anos escrevem, agora sob o desafio de estabelecerem diálogos produtivos entre académicos com trabalho reconhecido e funcionários do desenvolvimento. 
Numa publicação com o sugestivo título Legal Pluralism and Development: Scholars and Practitioners in Dialogue reconhece-se o falhanço das teorias e das políticas de desenvolvimento que ignoraram a ubiquidade do pluralismo jurídico ou a encararam como um constrangimento ao desenvolvimento, um defeito a superar em nome da modernização e da construção do Estado de direito. Acreditava-se que a transformação dos sistemas normativos era um exercício puramente técnico e produziram-se esforços para codificar e transformar tudo o que cabia no domínio dos sistemas informais em sistemas mais legíveis e uniformes sob o guarda-chuva do Estado. É hoje evidente, inclusive para o Banco Mundial, que, apesar dos largos recursos despendidos ao longo de décadas, muitos dos sistemas de justiças estatais permaneceram disfuncionais, enquanto os sistemas informais continuam a operar (Sage; Woolcock, 2013). Em 2009, foi promovido um encontro em Washington, institucionalmente organizado pelo United States Institute of Peace e pela George Washington University, que envolveu pessoas ligadas ao Programa Justice for the Poor, sob o tema Customary Justice and Legal Pluralism in War-Torn Societies. O seminário resultou numa publicação com o mesmo nome, na qual são apresentados estudos de caso sobre o papel dos sistemas de justiça costumeira em sete países: Moçambique, Guatemala, Timor-Leste, Afeganistão, Libéria, Iraque e Sudão. Na introdução da publicação, pode ler-se que o referido programa do Banco Mundial retirou da sombra os estudos sobre o pluralismo jurídico e a justiça costumeira e sublinha-se a importância de articular estes temas não só no âmbito do setor da reforma da justiça, mas de iniciativas de desenvolvimento mais vastas (Isser, 2011).

Este entusiasmo pela justiça informal não é prerrogativa do Banco Mundial. As Nações Unidas, através das suas agências e organismos, como a UNICEF, o PNUD ou a UN Women têm defendido que está na hora de integrar os sistemas de justiça informal em programas de desenvolvimento 
amplos que incluam a promoção dos direitos humanos e o acesso à justiça para todos/as. Uma publicação intitulada Informal Justice System admite a centralidade dos sistemas informais de justiça, reconhecendo a sua acessibilidade e a capacidade para providenciarem soluções mais baratas, rápidas e culturalmente relevantes. Nesse sentido, assume a importância de aprofundar o conhecimento sobre os sistemas informais e a forma de interagir com os mesmos com vista a fortalecer os direitos humanos, o Estado de direito e o acesso à justiça, reconhecendo a inadequabilidade das abordagens one-size-fits-all. É manifesta a preocupação com as violações dos direitos humanos, embora se reconheça que o problema se coloca também ao nível da justiça formal, afirmando que os dois tipos de sistemas podem violar direitos humanos, reforçar a discriminação e negligenciar princípios de procedimentos justos (UN Women, PNUD, UNICEF, 2012).

Esse estudo de 2012 não surgiu de um vazio. Em 2006, uma publicação com a chancela do PNUD argumentava sobre a importância da justiça informal e a necessidade de envolver estes sistemas de justiça em programas abrangentes de promoção do acesso à justiça. Tal como o relatório anterior, mostra preocupação com as situações de discriminação, em particular contra a mulher, mas argumenta que a solução não passa por ignorar a relevância dessas instâncias, defendendo a criação de iniciativas graduais que melhorem os padrões de justiça, enfatizando a inexistência de uma solução geral e a necessidade de pensar soluções específicas para cada problema (Wojkowska, 2006).

Roland Jansen reflete sobre o que terá levado os doadores a perseguirem, durante tanto tempo, uma reforma jurídica cega à realidade óbvia do pluralismo jurídico. Aponta sete razões para essa cegueira: a ausência de memória sobre a história que revela a importância das circunstâncias específicas; os constrangimentos organizacionais e operativos, que envolvem, entre outros fatores, avaliações pouco aprofundadas, 
assentes no desconhecimento dos contextos; as lentes conceptuais do centralismo jurídico forte; o desinteresse em contrariar as elites políticas locais que pretendem fortalecer o sistema judiciário; as preocupações geopolíticas sobre o poder do islão; a aversão normativa a algumas práticas promovidas pelos sistemas jurídicos não-estatais conflituantes com os direitos humanos; e o mandato insuficiente por parte das instituições que promovem o Estado de direito. Ora, de acordo com o autor, o único fator que desapareceu foi a conceção forte de centralismo jurídico, que negava a existência de outros sistemas jurídicos. Ainda que esta ideologia não tenha sido completamente abandonada, pois o direito estatal é ainda considerado o centro do universo e não apenas mais um planeta, é agora possível pensar na relação entre o sistema jurídico estatal e não estatal no âmbito das reformas jurídicas. No entanto, não é claro como se pode promover essa relação e não é certo que os resultados conduzam à democratização da justiça. Os modelos conhecidos são os do período colonial e assentam sobretudo na codificação do direito costumeiro ou na incorporação das instituições locais pelas instituições estatais. Além disso, mantém-se a tendência para considerar que os sistemas formais e não formais são compatíveis e semelhantes e, finalmente, o sistema jurídico estatal é, em última análise, o elemento superior que assegura a justiça e a segurança. Com base nesta argumentação, Janse conclui que o abandono do centralismo jurídico não é suficiente para promover uma viragem credível em direção ao pluralismo jurídico. No entanto, o autor termina com uma nota otimista, afirmando que um corpo recente de trabalho programático e analítico tem apresentado aspetos positivos, sendo menos dogmático, estando disposto a assumir posições políticas, usando diferentes disciplinas e reconhecendo os limites da influência externa (Janse, 2013).

Centrando-me no último ponto mencionado, o reconhecimento da incapacidade de introduzir um Estado de direito alheio ao contexto, ten- 
do a desenvolver uma leitura menos confiante que a de Janse. Chegou o momento de reconhecer as exclusões criadas por um modelo colonial de Estado de direito e valorizar a pluralidade jurídica, ou estamos perante uma tentativa das instituições internacionais de alcançarem os objetivos que lhes escaparam no passado? Uma crítica há muito apontada à justiça informal, seja no âmbito do movimento de Resolução Alternativa de Conflitos nascido nas décadas de 1960 e 1970 nos EUA, ou do pluralismo jurídico encontrado nas sociedades do Sul, prende-se com a cooptação da justiça informal pelo Estado, com vista ao controlo da população. Van Krieken (2001) usou a metáfora do "Cavalo de Troia" para ilustrar este conjunto de preocupações. Boaventura de Sousa Santos, referindo-se aos movimentos de informalização ocorridos nas sociedades ocidentais, afirmou que o Estado, ao informalizar-se, assumindo um formato que se aproxima do de governo indireto, "tenta cooptar as relações sociais continuadas", isto é, tende a articular o "poder cósmico" (poder centralizado, fisicamente localizado em instituições formais e hierarquicamente organizado) com o poder caósmico (poder inerente às relações e interações sociais sempre que estas são desiguais ou assimétricas). O modelo colonialista do governo indireto assentava precisamente no reconhecimento, na diferenciação e na instrumentalização da legitimidade das instituições locais conquistadas, assumindo a separação entre não nativos e nativos, que cuidadosamente separava pelas distintas ordens normativas a que os sujeitava (direito civil e direito costumeiro); e entre governo colonial, que se ocupava dos problemas gerais de gestão de recursos, e governo indígena, que assentava na construção de administrações nativas e dependia da ligação com os chefes tradicionais (seletivamente reconstituídos ou criados à medida das necessidades do poder colonial) (Mamdani, 1996; Meneses, 2007). 
Os conceitos de pluralismo jurídico e justiça informal adquiriram uma popularidade sem precedentes, mas foram colocados ao lado de um conjunto de palavras que sempre conhecemos associadas ao pensamento linear e à ideia de progresso, como políticas de desenvolvimento, eficácia, agências doadoras, reforma do setor, capacitação, medição de impacto ou pobreza. Esta abordagem pluralista é hoje central no âmbito do programa do Banco Mundial intitulado "Justiça para os pobres", que se autodefine como programa de apoio à emergência de sistemas de justiça equitativa, focado na identificação e apoio aos resultados substantivos da justiça e não na busca de estruturas institucionais pré-determinadas, a operar em países em que o pluralismo jurídico apresenta um desafio de desenvolvimento particular. Se o conceito de pobreza é, em si mesmo, discutível, por evocar uma lógica de desenvolvimento linear dentro do paradigma definido pelo Norte, o conceito de justiça para pobres é francamente problemático e remete-nos para a ideia de justiça dualista ou, nos termos de Mamdani, de Estado bifurcado, que distingue cidadãos de primeira classe e cidadãos de segunda classe,

[...] um mundo em que a linha divisória entre os humanos e os outros menos humanos é uma linha entre os que trabalham na terra e os que não. Este mundo é habitado por subjugados de um lado e cidadãos no outro; a sua vida é regulada pela lei costumeira de um lado e a lei moderna do outro; as suas crenças são rejeitadas como pagãs de um lado, mas mantêm o estatuto da religião no outro; os momentos estilizados nas vidas quotidianas são considerados rituais de um lado e cultura no outro; a sua atividade criativa é considerada artesanato de um lado e glorificada como arte do outro; a sua comunicação verbal é diminuída como conversa vernacular de um lado e elevada como discurso linguístico do outro; em suma, o mundo dos "selvagens" barricado, nos atos e nas palavras, do mundo dos "civilizados" (Mamdani, 1996: 61). 


\section{Pode o pluralismo jurídico desafiar as epistemologias do Norte? A provincialização do direito e a ecologia de direitos e de justiças}

Face aos cenários apresentados no ponto 1 e no ponto 2, a questão que se impõe é: em que medida o pluralismo jurídico, enquanto conceito e realidade empírica, pode contribuir para as Epistemologias do Sul ou, dito de outro modo, como pode desafiar o pensamento abissal? Falar de Sul, neste contexto, é falar de silenciamento, invisibilidade, sofrimento humano causado pelo capitalismo, pelo colonialismo e pelo patriarcado e é falar também da resistência, em que cabe uma multiplicidade de conhecimentos excluídos do mapa, invisibilizados, desperdiçados pela modernidade (Santos, 1995). O argumento que aqui defendo é de que o pluralismo jurídico pode ser um instrumento de descolonização, no âmbito de uma sociologia jurídica das ausências e das emergências, se for reformulado enquanto ecologia jurídica ou ecologia de direitos e de justiças (Araújo, 2012).

Se o direito moderno replicou a colonialidade da ciência moderna, a ecologia de direitos e de justiças reproduz a lógica da ecologia de saberes e envolve a rejeição das cinco monoculturas, confrontando a conceção liberal do direito e da justiça com a diversidade de direitos e de justiças que existem no mundo. A proposta não ignora o legado dualista colonial que usou a pluralidade para dividir o mundo entre civilizados e incivilizados. No entanto, ao mesmo tempo que recusa as hierarquias impostas pelo colonialismo e pela colonialidade, rejeita o universalismo abstrato do direito moderno e propõe o reconhecimento da pluralidade e a transformação das diferenças verticais em diferenças horizontais. Recusando a romantização da realidade, alarga o cânone jurídico, evocando a ideia de copresença radical, opondo-se a leituras evolucionistas assentes na monocultura do tempo linear. 
Classificações como o exótico, o tradicional residual, o costumeiro inferior, a alternativa por oposição à norma moderna dão lugar a conceções jurídicas constitutivas de processos de aprendizagens jurídicas recíprocas. O direito moderno, seja na forma do Estado de direito ou na conceção de direitos humanos, não é excluído, mas deve ser "provincializado" e "desparoquializado". O primeiro conceito é adaptado para os direitos humanos a partir da crítica de Chakrabarthy ao pensamento europeu e passa por retirar aos direitos humanos a máscara de universalidade, renovando-os a partir das margens e deslocando-os do centro (Woessner, 2013). O segundo foi desenvolvido por William Twinning, no âmbito de uma crítica à teoria jurídica ocidental sobre o mundo, e argumenta a necessidade desta ver além de si própria, reconhecendo teorias jurídicas com origem no mundo colonizado (Twinning, 2013).

Este exercício é extremamente difícil, estando sujeito aos mesmos desafios da ecologia de saberes, envolvendo o exercício de desaprendizagem das ciências sociais que constituíram o Sul como "o outro" e o Norte como o "nós" (Santos, 1995). Boaventura de Sousa Santos argumenta que o que melhor identifica o Sul é o seu silenciamento e que o epistemicídio conduzido pelo Norte foi quase sempre acompanhado por um linguagicídio. O Sul foi duplamente silenciado: porque alegadamente não tinha nada para dizer e porque não tinha linguagem para o fazer (Santos, 1995). Ora a questão da linguagem é crucial quando falamos de uma ecologia de direitos e de justiças, porque, ainda que estejamos disponíveis para reconhecer outras realidades jurídicas, tem sido difícil pensar outro meio de estabelecer pontes, sem que os termos em que se desenvolve o debate sejam definidos pelo direito moderno.

As Epistemologias do Sul tendem a privilegiar o estudo do que Santos designou por cosmopolitismo subalterno, isto é, as lutas de movimentos e organizações que resistem ao modelo de globalização hegemónico 
e à exclusão e reivindicam alternativas (Santos, 2002). No âmbito jurídico, é na "legalidade cosmopolita subalterna" que se centram as atenções, isto é, nas estratégias jurídicas em que assenta o cosmopolitismo subalterno ou, por outras palavras, no uso coletivo do direito para promover a globalização contra-hegemónica (Santos; Rodriguez-Garavito, 2005). No entanto, é preciso notar que, por um lado, estas estratégias exigem domínio da linguagem jurídica; e, por outro, propõem alterar o direito moderno e ampliá-lo, mas não subvertem a hierarquia que lhe assegura o topo.

No âmbito do pluralismo jurídico, a legalidade cosmopolita é identificada nas lutas dos movimentos indígenas da América Latina contra o capitalismo global predatório com base na reivindicação dos direitos locais e dos territórios ancestrais (Rodriguez-Garavito; Arenas, 2005) e na mobilização indígena pelo reconhecimento dos sistemas políticos e jurídicos ancestrais (Santos; Jiménez, 2012). Referindo-se aos processos de profundas reformas constitucionais que ocorreram no Equador e na Bolívia, Boaventura de Sousa Santos afirma podermos encontrar aí embriões de transformação paradigmática do Estado moderno. Segundo o autor, não se trata apenas do reconhecimento da diversidade cultural ou de um expediente que permita às comunidades locais e remotas resolverem pequenos conflitos no seu interior e garantir a paz social que o Estado não consegue por falta de meios materiais e humanos, mas de conceber a justiça indígena como parte importante de um projeto político de vocação descolonizadora e anticapitalista, uma segunda independência que rompa com os vínculos eurocêntricos que condicionaram os processos de desenvolvimento nos últimos duzentos anos (Santos; Jiménez, 2012). Se o otimismo é fundado, não é menos verdade que, uma vez transformada a Constituição, o poder da Assembleia Constituinte tem fim e é às elites políticas modernas que fica entregue o poder. Além disso, ainda que seja intercultural, a Constituição não deixa de ser um instrumento eurocêntrico e estar sujeito às diretrizes que vêm das regulações internacionais. 
Isto não significa que os processos não tenham uma importância extraordinária no âmbito das Epistemologias do Sul. O reconhecimento constitucional da pluralidade jurídica, da plurinacionalidade e da demodiversidade não tem aqui qualquer ligação com as políticas de reconhecimento da justiça informal que têm vindo a ser defendidas pelo Banco Mundial. Resultaram de lutas que nasceram da rua, dos silenciados pela colonialidade e denunciaram a linha abissal. No entanto, as Epistemologias do Sul, no âmbito de uma ecologia de direitos e de justiças, devem ser mais amplas e incluir outras vozes e direitos subalternos que se exprimem noutros termos e não se ouvem fora da sociedade civil incivil. ${ }^{8} \mathrm{O}$ inovador conceito de "direito achado na rua" (Sousa Junior, 2011) estende-se para lá do que é enunciado a partir dos movimentos sociais, incluindo o que Boaventura de Sousa Santos designou como "o direito dos oprimidos" (Santos, 2014b).

A ecologia de direitos e de justiças deve incluir as lutas jurídicas que florescem na interlegalidade dos encontros jurídicos e nas lacunas do Estado, ${ }^{9}$ as justiças comunitárias que emergem em zonas de contacto entre vários direitos e as estratégias que os cidadãos e as cidadãs usam face à diversidade de ordens jurídica que têm ao dispor numa paisagem jurídica híbrida (Araújo, 2014). O exercício que aqui proponho exige o esforço de des-pensar os quadros mentais eurocêntricos, pensar fora das dicotomias que invocam a ideia de caos/ordem e identificar realidades que temos

\footnotetext{
${ }^{8}$ Esta categoria faz parte dos três tipos de sociedade civil ou três círculos definidos por Boaventura de Sousa Santos: a sociedade civil íntima, a sociedade civil estranha e a sociedade civil incivil. A sociedade civil íntima é a esfera da híper-inclusão; a sociedade civil estranha é o círculo intermédio, composto por cidadãos com uma inclusão moderada e onde os cidadãos podem exercer de forma mais ou menos livre os seus direitos cívicos e políticos, mas têm acesso escasso aos direitos sociais, económicos e culturais; a sociedade civil incivil é o círculo exterior, composto pelos cidadãos excluídos do contrato social e que habitam a zona de invisibilidade (Santos, 2002).
}

${ }^{9}$ Sobre o conceito de interlegalidade, ver Santos, 2002. 
dificuldade em classificar, exige quadros teóricos apropriados e traz-nos complexos desafios metodológicos.

Tendo em vista o alargamento do cânone do direito e da justiça, num horizonte de luta contra o desperdício da experiência jurídica a partir do conhecimento e do reconhecimento da realidade tão vasta que cabe na proposta de ecologia de justiças, realizei entre 2008 e 2010 um estudo no centro urbano da cidade de Maputo, capital de Moçambique, um país juridicamente muito plural. O projeto de investigação não definia as instâncias concretas a estudar, mas uma área geográfica onde deveria mapear o que designei por justiças comunitárias. As justiças comunitárias são uma categoria definida sobretudo pela negativa, como instâncias não judiciais de resolução de litígios, que recorrem a uma terceira parte imparcial. Se esta fluidez de fronteiras pode ser vista como limitação, é a flexibilidade do conceito que o torna um instrumento epistemológico relevante, com elasticidade para incluir instâncias esperadas e inesperadas. O objetivo era pois "escutar" o terreno mais livre de preconceitos, evitar a exclusão de estruturas relevantes apenas por não encaixarem numa definição fechada e ter a possibilidade de dar conta de uma paisagem móvel, híbrida e diversificada, nem sempre previsível. Aceitei a possibilidade de uma realidade inesperada e encontrei-a no seio de instituições do Estado que, formal ou informalmente, fazem mediação de conflitos e numa organização de direitos humanos que acolhe diferentes ordens jurídicas da sociedade.

As justiças comunitárias mais surpreendentes foram três híbridos jurídicos: as esquadras de polícia, que resolvem por consenso os designados "casos sociais", de que que se destacam os conflitos ocorridos na esfera do mercado (formal e informal); o Gabinete Modelo de Atendimento à Mulher e Criança Vítimas de Violência (GAMC), uma instância estatal, nascida no contexto de convenções e discussões internacionais para deslegitimar e combater a violência contra as mulheres na esfera doméstica; 
e a Associação Nós por Exemplo, uma pequena associação de defesa dos direitos das mulheres onde a interlegalidade dá lugar às combinações jurídicas mais criativas, isto é, acordos variados, exequíveis, que transcendem o direito estatal e o direito dos espaços doméstico e da comunidade, indo ao encontro das expetativas das partes.

Não cabe aqui apresentar os resultados desse trabalho, faço-o em outros lugares (Araújo, 2014, 2015). Mais importante do que as instâncias encontradas foi o contacto com as estratégias de argumentação jurídica das partes, os diferentes discursos que emergiam durante as discussões dos casos e as formas complexas que assume a interlegalidade, incompreensíveis unicamente a partir do direito estatal ou de versões fechadas do direito costumeiro. A Lei da violência doméstica contra a mulher, ${ }^{10}$ compatível com os instrumentos internacionais de direitos humanos e resultante de um longo processo de discussão pública, que envolveu organizações da sociedade civil (íntima), é simbólica na forma como se produzem exclusões no espaço público e das suas consequências. A prática revelou-a desfasada da realidade das instituições e das preocupações da grande maioria das mulheres que procurava ajuda com mais expetativas de uma solução que garantisse a sobrevivência e a segurança familiar do que de punições. Nos Gabinetes de Atendimento à Mulher e Criança, onde a lei devia ser seguida, os processos de aconselhamento e mediação estavam entregues a dinâmicas individuais das agentes, em que o direito da comunidade se articulava com um entendimento precário dos direitos humanos e da lei mencionada, por exemplo, condenando-se a violência contra a mulher ao mesmo tempo que se produziam julgamentos morais sobre os seus comportamentos, em particular nos casos de violência sexual. Ao contrário, na Associação Nós por Exemplo, as soluções eram demoradas, as partes eram ouvidas longamente, procurando-se acordos

\footnotetext{
$\overline{10}$ a Lei no $29 / 2009$.
} 
exequíveis que transcendiam qualquer receita, construídos a partir de ordenamentos jurídicos combinados. Aqui, a flexibilidade andava de mãos dadas com a empatia, as necessidades específicas dos casos, a vontade e as propostas das partes envolvidas, o contexto de ocorrência do conflito e as garantias oferecidas pelos vários direitos em presença.

Do trabalho, foi possível retirar um conjunto de aprendizagens e desafios para a investigação, de que eu destaco a necessidade de escutar os discursos jurídicos que escapam às discussões públicas e se produzem no dia-a-dia dos cidadãos e das cidadãs em espaços como o das organizações mencionadas. Os debates da sociedade civil, como no caso da lei da violência contra a mulher, tendem a excluir uma imensa maioria da sociedade civil incivil, silenciada. As consequências vão além do facto de a lei não servir os interesses dos cidadãos ou das cidadãs, mas tender a ser desvirtuada nas malhas de um Estado desconhecido pelo legislador e pelas organizações que o apoiaram, um Estado altamente heterogéneo, ${ }^{11}$ cujas práticas são permeadas por uma pluralidade jurídica que pode assumir contornos violentos quando deixa de ter que se legitimar numa atuação avaliada positivamente (como acontece na maioria das instâncias comunitárias) e passa a usufruir da autoridade do Estado e, por vezes, de um alegado uso legítimo da violência. Proteger a mulher da violência em casa é um projeto a construir a par da luta pelos seus direitos sociais e económicos, assim como da luta pela sua autorrepresentação. A luta jurídica contra o patriarcado tem que estar de mãos dadas com a luta contra o capitalismo, mas também contra o colonialismo, que exclui as oprimidas das decisões do seu próprio destino.

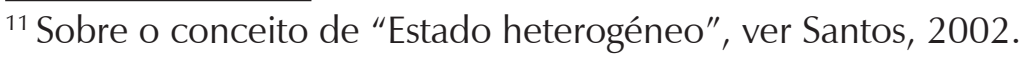




\section{Conclusão}

O Estado de direito, enquanto modelo exportável, assenta nos princípios jurídicos modernos, reconhece as agências internacionais que asseguram a hegemonia do modelo capitalista neoliberal e reivindica a universalidade dos direitos humanos formulados a partir de uma perspetiva eurocêntrica, ao mesmo tempo que os evoca de forma seletiva, de acordo com os seus interesses. Esse modelo jurídico, que se apresenta como técnico e não político, respeita mais os mercados do que as pessoas, atropela ordenamentos jurídicos que regem outras culturas e outras organizações políticas e cria a sociedade civil incivil. Neste texto, defendo que o direito, enquanto duplo da ciência, é um instrumento de expansão do colonialismo e do capitalismo, sendo responsável pela invisibilização jurídica e pelo silenciamento de sujeitos. Nesse sentido, defendo a recuperação do conceito de pluralismo jurídico num horizonte de reconhecimento de outros universos jurídicos.

O conceito deve, no entanto, ser escrutinado e reconfigurado. As Epistemologias do Sul são um projeto epistémico e político. Não propõem apenas uma descrição da pluralidade, mas uma transformação das hierarquias impostas pela modernidade. $\mathrm{O}$ fetichismo do primado do direito moderno tem que ser ultrapassado. O pluralismo jurídico é então proposto como instrumento conceptual de uma ecologia de direitos e de justiças que pretende não só reconhecer a pluralidade, mas criar pontes de diálogo que permitam promover aprendizagens jurídicas recíprocas entre o Sul e o Norte, ampliando o horizonte de possibilidades políticas. Como a ecologia de saberes, o processo de ecologia de direitos e justiças requer o exercício das cinco ecologias que contrariam as cinco monoculturas, envolvendo a visibilidade, a copresença, a horizontalidade, a desglobalização do local relativamente à globalização hegemónica, e a recuperação de ordenamentos jurídicos que regulam sistemas produtivos 
que a ortodoxia jurídica capitalista não reconhece. Este é um exercício muito ambicioso que, no meu entender, deve incluir o cosmopolitismo subalterno e a legalidade cosmopolita, mas ir mais além, estendendo o direito achado na rua ao direito dos oprimidos, cuja voz ecoa na sociedade civil incivil, mas não se expressa na linguagem dos movimentos sociais.

Esta proposta exige ousar nas metodologias de investigação, de modo a permitirem a inclusão de narrativas e lutas que se exprimem em termos que as categorias ocidentais têm dificuldade em reconhecer. $\mathrm{O}$ conceito de ecologias de direitos e de justiças não se circunscreve ao terreno convencional do pluralismo jurídico. Se a justiça social requer justiça cognitiva, exige também o reconhecimento da pluralidade jurídica, com uma forte dimensão de análise política. Mais do que a velha discussão sobre o significado do direito, importa o que expressam politicamente os ordenamentos jurídicos desperdiçados pelo cânone moderno, que regem outras organizações políticas, outras democracias, outras economias e outras gramáticas jurídicas.

Sara Araújo é Doutora em "Direito, Justiça e Cidadania no Século XXI", pela Universidade de Coimbra (Portugal). É investigadora do Centro de Estudos Sociais da Universidade de Coimbra e co-coordenadora do Projeto "ALICE, Espelhos Estranhos, Lições Imprevistas". $\$ sara@ces.uc.pt

\section{Referências}

1. ARAÚJO, S. Toward an ecology of justices: an Urban and Rural Study of Mozambican Plurality. In: KYED, Helene et. al. (Org.), The dynamics of legal pluralism in Mozambique. Maputo: Kapicua, 2012.

2. ARAÚJO, S. Ecologia de Justiças a Sul e a Norte, Cartografias Comparadas das Justiças Comunitárias em Maputo e Lisboa. 2014. 542p. Doutormento em "Direito, Justiça e Cidadania no Século XX", Faculdade de Economia da Universidade de Coimbra, Coimbra 
3. ARAÚJO, S. Desafiando a colonialidade. A ecologia de justiças como instrumento da descolonização jurídica. Hendu - Revista Latino-Americana de Direitos Humanos, v. 6, n.1. 2015. p 26-46.

4. CHIMNI, B.S., Third world approaches to international law: a manifesto, International Community Law Review, v. 8, 2006, p. 3-27.

5. DUSSEL, E. Agenda for a South-South Philosophical Dialogue. Human Architecture: Journal of Sociology of Self-Knowledge, v. 1. 2013, p. 3-18.

6. DUVE, T. Introduction. In: DUVE, T. (Org.) Entanglements in Legal History: Conceptual Approaches. Frankfurt am Main: Max Planck Institute for European Legal History. 2014. p. 3-25.

7. FITZPATRICK, P. The Mythology of Modern Law. London and New York: Routledge, 1992

8. GALINDO, G.R.B. Legal Transplants between Time and Space In: DUVE, T. (Org.), Entanglements in Legal History: Conceptual Approaches, Frankfurt am Main: Max Planck Institute for European Legal History, 2014. p. 129-148.

9. GRIFFITHS, J. What is Legal Pluralism? Journal of Legal Pluralism, v. 24. 1986, p. 1-55.

10. ISSER, D. H. Introduction. Shifting Assumptions from Abstract Ideals to Messy Realities. In: ISSER, Deborah H. (Org.) Customary Justice and the Rule of Law in War-Torn Societies. Washington D. C.: USIP Press Books, 2011.

11. JANSE, R. A Turn to Legal Pluralism in Rule of Law Promotion? Erasmus Law Review, v. 6, n. 3/4, p. 181-190, 2013

12. KRIEKEN, R. Legal Informalism, Power and Liberal Governance. Social \& Legal Studies, v. 10, n. 1, p. 5-22, 2001.

13. MAMDANI, M. Citizen and Subject. Contemporary Africa and the legacy of late colonialism. Princeton, New Jersey: Princeton University Press, 1996

14. MATTEI, U.; NADER, L. Plunder: When the rule of law is illegal. Malden, Oxford, Victoria: Blackwell, 2008.

15. MENESES, M.P. Pluralism, Law and Citizenship in Mozambique. Coimbra: Oficina do CES, 291, 2007.

16. MUDIMBE, V.Y. The invention of Africa. Gnosis, philosophy and the order of knowledge. London: Indiana University Press, 1988.

17. QUIJANO, A. Colonialidade do poder e classificação social. In: SANTOS, B. de S.; MENESES, M.P. (Org.). Epistemologias do Sul. Coimbra: Almedina, 2009. 
18. RODRIGUEZ-GARAVITO, C.; ARENAS, L.C. Indigenous rights, transnational activism, and legal mobilization: the stuggle of the U'wa people in Colombia. In: SANTOS, B. de S.; RODRIGUEZ-GARAVITO C. (Org.), Law and Globalization from Below. New York: Cambridge University Press, 2005.

19. SAGE, C.; WOOLCOCK, M. Introduction. Legal Pluralism and Development Policy. Scholars and Practitioners in Dialogue. In: TAMANAHA, B. et. al. (Org.), Legal Pluralism and Development. Scholars and Practitioners in Dialogue. Cambridge: Cambridge University Press, 2013.

20. SAID, E. Orientalism. New York: Vintage Books, 1978

21. SANTOS, B. de S. Towards a New Common Sense. Law, science and politics in the paradigmatic transition. New York, London: Routledge, 1995

22. SANTOS, B. de S. Towards a New Legal Common Sense. London: Butterwords, 2002.

23. SANTOS, B de S. A gramática do tempo. Para uma nova cultura política. Porto: Edições Afrontamento, 2006

24. SANTOS, B. de S. Para além do Pensamento Abissal: Das linhas globais a uma ecologia de saberes, Revista Crítica de Ciências Sociais, v. 78, p. 3-6, 2007

25. SANTOS, B. de S. Os Processos da Globalização, Eurozine, 2008. Disponível em: http://www.eurozine.com/articles/2002-08-22-santos-pt.html [acesso em 5 de junho de 2012]

26. SANTOS, B. de S. Para uma revolução democrática da justiça. São Paulo: Cortez, 2011.

27. SANTOS, B. de S. Se Deus fosse um ativista dos direitos humanos. Coimbra: Editora Almedina, 2013.

28. SANTOS, B. de S. Epistemologies of the South. Boulder: Paradigm, 2014a.

29. SANTOS, B. de S. O direito dos oprimidos. Coimbra: Almedina, 2014b.

30. SANTOS, B. de S.; JIMÉNEZ, A.G. (Org.), Justicia indígena, plurinacionalidad e interculturalidad en Ecuador. Quito: Ediciones Abya Yala e Fundación Rosa Luxemburg, 2012.

31. SANTOS, B. de S.; RODRIGUEZ-GARAVITO, C. (Org.), Law and Globalization from Below. New York: Cambridge University Press, 2005

32. SOUSA JUNIOR, J. G. Direito como liberdade. O Direito achado na rua. Porto Alegre: Sérgio Fabris, 2011 
33. TWINNING, W. Human Rights, Southern Voices: Yash Ghai and Upendra Baxi. In: BARRETO J.-M. (Org.), Human Rights from a Third World Perspective: Critique, History and International Law. Cambridge: Cambridge Scholars Publishing, 2013, p. 256-310

34. UN WOMEN, PNUD, UNICEF. Informal justice systems. Charting a course for human rights-based engagement. UN Women, PNUD, UNICEF, 2012

35. WHITMAN, J.Q. Western legal imperialism: thinking about the deep historical roots, Theoretical Inquiries in Law, v. 10, n. 2, p. 305-332. 2009.

36. WOESSNER, M. Provincializing Human Rights? The Heideggerian Legacy from Charles Malik to Dipesh Chakrabarty. In: BARRETO, J.-M. (Org.), Human Rights from a Third World Perspective: Critique, History and International Law. Cambridge: Cambridge Scholars Publishing, 2013, p. 65-101

37. WOJKOWSKA, E. Doing Justice: How informal justice systems can contribute. United Nations Development Programme, Oslo Governance Centre, 2006. Disponível em: http://siteresources.worldbank.org/INTLAWJUSTINST/Resources/ EwaWojkowska.pdf._Acesso em 10 de Jun de 2015.

Recebido: 12.01.2016

Aceite: 13.04.2016 